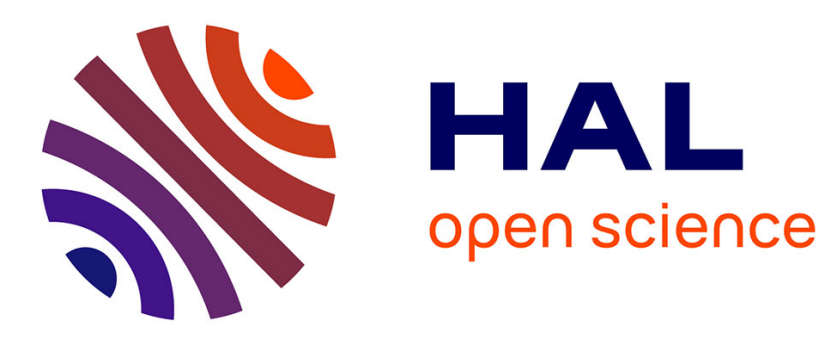

\title{
18. Étude de l'effet tunnel assisté par des impuretés dans le GaAs
}

\author{
C.B. Duke, R.D. Burnham, N. Holonyak, H.W. Korb
}

\section{To cite this version:}

C.B. Duke, R.D. Burnham, N. Holonyak, H.W. Korb. 18. Étude de l'effet tunnel assisté par des impuretés dans le GaAs. Revue de Physique Appliquée, 1970, 5 (6), pp.906-906. 10.1051/rphysap:0197000506090600 . jpa-00243488

\section{HAL Id: jpa-00243488 https://hal.science/jpa-00243488}

Submitted on 1 Jan 1970

HAL is a multi-disciplinary open access archive for the deposit and dissemination of scientific research documents, whether they are published or not. The documents may come from teaching and research institutions in France or abroad, or from public or private research centers.
L'archive ouverte pluridisciplinaire HAL, est destinée au dépôt et à la diffusion de documents scientifiques de niveau recherche, publiés ou non, émanant des établissements d'enseignement et de recherche français ou étrangers, des laboratoires publics ou privés. 


\title{
18. ÉTUDE DE L'EFFET TUNNEL ASSISTÉ PAR DES IMPURETÉS DANS LE GaAs
}

\author{
C. B. DUKE \\ Département de Physique, Materials Research Laboratory \\ and Coordinates Sciences Laboratory. Université de l'Illinois \\ à Urbana-Champaign, Urbana, Illinois. A. M. Andrew \\ R. D. BURNHAM, N. HOLONYAK Jr et H. W. KORB \\ Departement of Electrical Engineering and Material Research Laboratory. \\ Université de l'Illinois à Urbana-Champaign, Urbana, Illinois
}

Lors d'une étude précédente [1] nous avions observé un « canal photostimulé » pour le passage du courant dans des diodes de GaAs avec des impuretés d'Au (possible également avec d'autres impuretés) situées dans la zone de type $n$ de la charge d'espace. La caractéristique $I-V$ présente un important maximum photostimulé ou injection stimulée à

$$
200 \mathrm{meV} \leqslant \mathrm{eV} \leqslant 300 \mathrm{meV} \text {. }
$$

Seule la lumière de fréquence $h v>1,35 \mathrm{eV}$ stimule cette nouvelle possibilité. L'état d'impuretés responsable du courant supplémentaire persiste pour des temps de vie supérieurs à l'heure à $77^{\circ} \mathrm{K}$ et $4,2^{\circ} \mathrm{K}$. La photoluminescence centrée autour de $1.35 \mathrm{eV}$ à $77^{\circ} \mathrm{K}$ a été observée pour des états similaires dans des pastilles de GaAs avec Au diffusé et des couches épitaxiques poussées au-dessus de l'eutectique $\mathrm{Au}-\mathrm{Sb}$ dopé au Ge qui approxime le côté de type $n$ de la diode tunnel. Les couches sont dopées dans la gamme $n=3-5 \times 10^{18} \mathrm{~cm}^{-3}$ et présentent à $77^{\circ} \mathrm{K}$ des mobilités $\mu=8-10 \times 10^{2} \mathrm{~cm}^{2} / \mathrm{vs}$ et à $300{ }^{\circ} \mathrm{K}$ des mobilités de $5-6 \times 10^{2} \mathrm{~cm}^{2} / \mathrm{vs}$. Les diodes sont obtenues en alliant des alliages d'Au à des substrats dopés par du Ge ou $\mathrm{Sn}$ dans la gamme de $10^{19} \mathrm{~cm}^{-3} \lesssim p \lesssim 5 \times 10^{19} \mathrm{~cm}^{-3}$. Les substrats plus faiblement dopés conduisent à des systèmes qui présenteraient des maxima de courant supplémentaire plus élevés. Le mécanisme pour les maxima de courant supplémentaire est relié à un effet tunnel inélastique par l'intermédiaire d'excitations additionnelles des états d'impuretés photostimulés. Comme supposée, une structure au voisinage de la polarisation nulle est observée, elle est également attribuée à la présence des impuretés d'Au.

\section{Bibliographie}

[1] Holonyak (N.), Keune (D. L.), Burnham (R. D.), Duke (C. B.), Phys. Rev. Letters, 1970, 24, 589. 